\title{
La codificación y descodificación como proceso participativo y reflexivo en una investigación temática apoyada en TIC*
}

\author{
Liliana Villa-Vélez ${ }^{* * *}$ \\ Ana María Vásquez Velázquez ${ }^{* * *}$ \\ Yeferson Castaño-Pineda**** \\ Gloria Matilde Escobar-Paucar ${ }^{* * * * * *}$ \\ Miryam Bastidas Acevedo********* \\ Jaime Arturo Gómez Correa********* \\ Diana Paola Betancurth Loaiza**********

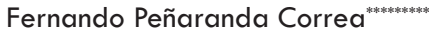 \\ Wilson Bolívar-Buriticá
}

\begin{abstract}
* Artículo de investigación científica y tecnológica. Este producto se derivó del proyecto de investigación con código SIIU 2016-12986, titulado Investigación temática para la construcción de una propuesta educativa sobre la crianza apoyada en TIC, en la vereda Granizal, Bello, 2017-2020, el cual fue financiado por la Universidad de Antioquia mediante la Convocatoria Programática 2016 Área Ciencias Sociales, Humanidades y Artes, del Comité para el Desarrollo de la Investigación (CODI). La primera autora recibió financiación de Colciencias en la convocatoria 647 de 2014 para la formación doctoral.
\end{abstract}

** Doctora en Salud Pública. Facultad Nacional de Salud Pública,

Universidad de Antioquia.

Correo electrónico: liliana.villa@udea.edu.co

ORCID: https://orcid.org/0000-0001-5571-412

*** Doctora en Educación. Facultad de Educación, Universidad de Antioquia.

Correo electrónico: anam.vasquez@udea.edu.co

ORCID: https://orcid.org/0000-0002-5083-1748

***** Magíster en Salud Pública. Facultad Nacional de Salud Pública, Universidad de Antioquia. Correo electrónico: yeferson.castano@udea.edu.co ORCID: https://orcid.org/0000-0003-0172-1021

****** Magíster en Salud Pública. Facultad de Odontología, Universidad de Antioquia. Correo electrónico: matilde.escobar@udea.edu.co; gescobarp@gmail.com ORCID: https://orcid.org/0000-0002-4721-4749

******* Magíster en Salud Colectiva. Facultad de Medicina, Universidad de Antioquia. Correo electrónico: miryam.bastidas@udea.edu.co ORCID: https://orcid.org/0000-0003-0173-1270

******** Especialista en Epidemiología y en Teorías y Métodos de Investigación Social. Facultad de Medicina, Universidad de Antioquia.

Correo electrónico: jaime.gomez@udea.edu.co

ORCID: https://orcid.org/0000-0001-9926-7087

********* Doctora en Salud Pública. Facultad de Ciencias para la Salud, Universidad de Caldas. Correo electrónico: diana.betancurth@ucaldas.edu.co ORCID: https://orcid.org/0000-0001-7620-2336

********** Doctor en Ciencias Sociales Niñez y Juventud. Facultad Nacional de Salud Pública, Universidad de Antioquia.

Correo electrónico: fernando.penaranda@udea.edu.co

ORCID: https://orcid.org/0000-0002-8863-5566

$* * * * * * * * * *$ Doctor en Educación. Facultad de Educación, Universidad de Antioquia.

Correo electrónico: wilson.bolivar@udea.edu.co

ORCID: https://orcid.org/0000-0003-2347-1916 


\section{Resumen}

Objetivo: presentar una experiencia de educación popular en crianza con mujeres de un asentamiento periférico de Medellín. Metodología: se desarrolló una investigación-acción que incluyó procesos de codificación y descodificación -los cuales están enmarcados en la investigación temática propuesta por Freire- con el apoyo de las tecnologías de la información y la comunicación (TIC). Se elaboraron códigos mediante videos, historias y audios, los cuales fueron convertidos en contenidos educativos digitales, que posteriormente se descodificaron con las participantes. Resultados: la codificación partió de vivencias comunes, trascendió lo singular y avanzó hacia la reconfiguración de relaciones educador-educando. La descodificación, por su parte, recreó de manera crítica su mundo y sus situaciones límite, para fortalecer la reflexión, la problematización y la participación ciudadana. Conclusión: la experiencia construyó alternativas en educación para la salud y crianza, propias de una educación transformadora, con el uso de las TIC.

Palabras clave: participación comunitaria, TIC, educación sanitaria, educación comunitaria, cambio social, salud, codificación, Tesauro de la Unesco. 


\title{
Coding and Decoding as a Participatory and Reflective Process in Thematic Research Supported by ICT
}

\begin{abstract}
Objective: to present an experience of popular education in childrearing with women from a peripheral settlement in Medellín. Methodology: an Action Research, framed in the thematic research proposed by Freire, that included coding and decoding processes was carried out with the use of Information and Communication Technologies. Codes were developed through videos, stories, and audios, which were converted into digital educational content and, subsequently, decoded with the participants. Results: the codification process was based on common experiences, transcending the singular and advancing towards the educator-learner relationships reconfiguration. The decoding process critically recreated the participants' world and its borderline situations to strengthen reflection, problematization, and citizen participation. Conclusion: the experience presents alternatives in education for health and childrearing based on a transformative education with the use of ICT.
\end{abstract}

Keywords: community participation, Information and Communication Technologies, health education, community education, social change, health, codification, Unesco thesaurus.

\section{Codificação e decodificação como processo participativo e reflexivo em pesquisas temáticas apoiadas pelas TIC}

\section{Resumo}

Objetivo: É apresentada uma experiência de educação popular sobre criação com mulheres de um assentamento periférico de Medellín. Metodologia: Foi realizada uma Pesquisa-Ação 
que incluía processos de codificação e decodificação enquadrados em uma Pesquisa Temática apoiada pelas TIC. Os códigos foram desenvolvidos por meio de vídeos, histórias e áudios, convertidos em conteúdo educacional digital, que posteriormente foi decodificado nos círculos de criação. Resultados: A codificação partiu de experiências comuns, transcendeu o singular e avançou em direção à reconfiguração das relações educador-educador. A decodificação, por sua vez, recriou criticamente seu mundo e suas situações limítrofes, fortalecendo a reflexão, a problematização e a participação do cidadão. Conclusão: A experiência apresenta alternativas de educação para a saúde e a educação, típicas de uma educação transformadora, com o uso das TIC.

Palavras-chave: participação da comunidade, tecnologia da informação, educação em saúde, mudança social, saúde, codificação.

\section{Introducción}

El artículo presenta una experiencia de educación popular que integra la educación y la investigación-acción. El énfasis está en mostrar un proceso de codificación y descodificación en el marco de una propuesta educativa sustentada en la investigación temática. Lo anterior como aplicación del método de educación popular planteado por Paulo Freire (Freire, 2005). La propuesta educativa partió de la comprensión de las crianzas que ejercen mujeres de una comunidad asentada en la periferia de la ciudad de Medellín; y los contenidos estuvieron en coherencia con los intereses de las participantes.

Entender la crianza como complejo histórico, sociocultural y ontológico que se desarrolla con individuos particulares y en contextos concretos (Peñaranda, 2011), implica que el proceso educativo trascienda las vidas y las crianzas individuales. De igual manera, busca extender la mirada hacia los asuntos que facilitan o limitan 
las crianzas posibles, y fortalecer el ejercicio de la ciudadanía, la movilización social y la garantía de los derechos, todo para la búsqueda de mejores oportunidades de realizar la vida y la crianza que las personas valoran.

La corriente de educación popular inscrita en un paradigma latinoamericano reivindica el papel político de la educación para la transformación de la sociedad y la participación directa de las comunidades en las decisiones que los afectan. De igual modo, propone una práctica pedagógica participativa, colaborativa y cooperativa, en la que los sujetos son agentes constructores de los saberes (Mejía, 2013; Torres, 2011). Asimismo, constituye una oportunidad para replantear las maneras en las que se lleva a cabo la educación para la salud, en el marco de una salud pública con compromisos éticos y políticos frente a las formas pedagógicas que incorpora; esto con la intención de no reproducir las injusticias sociales (Villa-Vélez, 2020). Lo anterior implica poner el foco tanto en las metas como en el proceso educativo. Así mismo, posibilita explorar las motivaciones y analizar la escucha dialéctica, a través de metáforas en la enseñanza y el aprendizaje, para partir de las historias propias y construir nuevas (Zanchetta et ál., 2012).

Varias experiencias investigativas han demostrado las posibilidades de las tecnologías de la información y la comunicación (TIC) para potenciar la participación y la movilización social en la construcción de ciudadanías activas (Landow, 2009). Se han consolidado propuestas que apoyan y amplían la participación ciudadana al entregar información, compartir opiniones y puntos de vista, debatir, argumentar e, incluso, constituir redes de cambio social (Castells, 2001).

El uso de las TIC le permite a los sujetos compartir sus experiencias y conocimientos, a la vez que construye y resignifica saberes y prácticas, todo en un ejercicio colectivo que fortalece los vínculos de la comunidad y amplía los ideales de una sociedad pluralista y democrática (Martín et ál., 2005; Rueda, 2011). En un mundo ampliamente interconectado, los medios se convierten en una alternativa para el desarrollo de procesos argumentativos, 
desde los cuales las personas se reconocen como parte de un colectivo, aprenden a respetar las diferencias de opinión y se fortalece la tolerancia y la capacidad para la búsqueda de acuerdos.

Hacen falta experiencias en las que las propuestas de educación para la salud superen las visiones instrumentales de las TIC y recurran a categorías vinculantes al ejercicio de la formación: aprender a pensar y promover el pensamiento crítico. Dichas propuestas -en contraposición a la educación bancaria- deben fomentar la reflexión y el ejercicio de la autonomía (Bermúdez, 2015) y - articuladas a dinámicas sociales, económicas, históricas y culturales - volver la mirada a la reflexión en y con las comunidades sobre la vida y las acciones para su transformación. El objetivo de este artículo es presentar la codificación y descodificación en el marco de la investigación temática, como proceso participativo y reflexivo en el desarrollo de una educación para la salud apoyada en TIC.

\section{Metodología}

Se presenta la ruta metodológica para codificar y descodificar con la comunidad; esto desde una investigación que se nutrió de los postulados de la educación popular como corriente de la pedagogía crítica latinoamericana (Torres, 2011), y partió de la realidad concreta de las poblaciones. Se llevó a cabo un proceso educativo de investigación temática fundado en el método propuesto por Paulo Freire y orientado hacia la interpretación crítica de los problemas (Freire, 2005). Sobre esta base se construyó el diseño metodológico de esta investigación.

La investigación temática se opone a lo bancario de la educación, donde el conocimiento se transmite del sabio (educador-docente) a otro que es considerado ignorante (educando-alumno) (Freire, 2005). Por lo tanto, el proceso educativo debe involucrar al educando, para que construya los conocimientos que orientarán su transformación. En este sentido, el diálogo comienza con la construcción 
colectiva de los contenidos educativos, a partir de las expectativas, necesidades e intereses de los educandos. No se llega, entonces, con un programa previamente escrito para ser impartido.

A su vez, la investigación temática se cruza con la investigaciónacción como modalidad participativa (Bradbury y Reason, 2003) y como práctica social (Fals Borda, 2001) para educar en crianza. De esta forma, se diseñó una investigación que recogiera la experiencia como fuente de conocimiento y diera lugar a las participantes como protagonistas de sus propias vidas. Desde el punto de vista metodológico, la investigación temática propone realizar códigos y descodificarlos para avanzar hacia la construcción democrática de una propuesta educativa. En esta experiencia, los procesos de codificación y descodificación se desarrollaron con las participantes.

En la codificación se realizaron síntesis de las significaciones que las participantes daban a sus experiencias, que correspondían a códigos entendidos como estrategias didácticas que se usan para representar las experiencias y lograr un distanciamiento de las situaciones problemáticas o situaciones límite. Las participantes - cuyas vidas transcurren en condiciones de injusticia social extrema- experimentaban crianzas difíciles y con pocas oportunidades para ellas y sus hijos. Al abordar directamente estas situaciones se generan sensaciones de frustración, tristeza y desesperanza, que desmotivan a los educandos y no permiten avanzar hacia nuevos aprendizajes. En este sentido, trabajar con códigos y no directamente con los problemas, permitió poner la situación afuera para analizarla, identificarse con ella y avanzar hacia una comprensión más contextualizada, en la que tanto educadores como educandos participaron.

La construcción de los códigos se entiende como la posibilidad que tuvieron las participantes de proponer los temas, hacer parte del diseño y elaboración de estos y definir el sentido educativo de lo que querían compartir con otras personas. De esta manera podían integrar sus propios saberes y la comprensión que alcanzaban de la situación mediante el ejercicio colectivo hermenéutico. 
Con un subgrupo de participantes denominadas dinamizadoras (ocho líderes en el proceso, elegidas por las demás mujeres) se construyeron videos, relatos escritos y audios en los que se representaban personajes que ellas mismas caracterizaban. Estos códigos se convirtieron en contenidos educativos digitales, que se fueron organizando en una propuesta educativa en crianza susceptible de ser llevada al grupo completo de participantes.

La descodificación, a partir del diálogo y la reflexión grupal, hace posible pasar a una mejor comprensión de las situaciones límite (Freire, 2005). En la descodificación se presentaron los códigos a un grupo más amplio de participantes (entre 5 y 20), y se avanzó en el análisis crítico de la situación que representaba el código. Esto con el fin de tomar distancia de la situación problemática representada y construir un nuevo conocimiento. Dicho análisis se trabajó con preguntas que generaron diálogo y reflexión en el grupo. Esta forma de problematización buscaba enfrentar la mistificación y el conformismo frente a hábitos y tradiciones sobre la crianza, propiciar la deliberación responsable frente a lo justo e injusto, construir conocimientos y estimular la acción sobre sus realidades (Bermúdez, 2015).

El desarrollo metodológico tuvo un carácter emergente, en la medida en que la comprensión hermenéutica que se logró en el proceso permitió identificar temas generadores que corresponden a asuntos significativos que se extraen de la realidad con un fin educativo (Freire, 2005). Para este caso, las categorías emergentes como ser hija, ser madre y ser mujer se representaron en códigos desde las experiencias de las participantes. Dichos temas alimentaron, a su vez, la elaboración de nuevos códigos para la construcción de la propuesta de educación en crianza. Así, la propuesta recoge una visión de totalidad e incluso podría ser adaptada para desarrollarse en otros escenarios con problemáticas similares.

El estudio fue desarrollado en el sector más alejado de un asentamiento semiurbano e irregular, donde habitan aproximadamente 
25000 personas $^{1}$ y está conformado, principalmente, por sujetos en situación de desplazamiento forzado por la violencia provenientes de diferentes lugares de Colombia. Los pobladores no cuentan con infraestructura para saneamiento básico, viven en condiciones socioeconómicas precarias y sufren injusticias sociales.

El grupo de investigadores fue conformado por un equipo interdisciplinario de profesionales de las áreas de salud pública, medicina, enfermería, odontología, educación y administración, todos integrados en el trabajo comunitario y en espacios académicos de análisis y reflexión para acompañar el proceso educativoinvestigativo. Aunque cada sesión se planeaba con anticipación, los temas fueron tratados de manera flexible para dar espacio a los asuntos emergentes en el proceso, y así dar respuesta a las necesidades de las participantes en el marco de la propuesta de educación en crianza.

La codificación y descodificación se desarrollaron a través de encuentros educativos que denominamos círculos de investigación temática y se realizaron cada 15 días, durante dos años. Se llevaron a cabo en espacios comunitarios de la localidad para facilitar la asistencia de las mujeres, todas ellas cuidadoras de niños de diferentes edades e interesadas en los temas de educación en crianza. La convocatoria se realizó a partir de la base de datos de un proyecto previo desarrollado en la misma comunidad, mediante 20 visitas familiares en las que se presentó el proyecto y se hizo la invitación a participar. Como criterio de inclusión se consideró la disponibilidad e interés para asistir a las sesiones y tener niños a su cargo.

La investigación fue avalada por el Comité de ética de la investigación de la Facultad de Enfermería de la Universidad financiadora, acta n. ${ }^{\circ}$ CEI-FE 2017-48. El trabajo con los códigos generados implicó reflexiones éticas, que llevaron a limitar su uso al escenario comunitario de la misma investigación, con el fin de proteger

1. Debido a los compromisos de confidencialidad adquiridos con las participantes $y$ con la finalidad de proteger su identidad, no se presenta información detallada que permita identificar la zona donde se desarrolló la investigación. Cabe anotar que se trata de uno de los asentamientos con mayor cantidad de población en situación de desplazamiento forzado en Colombia. 
la identidad de las participantes y en respuesta al pacto de confidencialidad que se desarrolló en el ámbito de los círculos. Estos elementos se abordarán en detalle con los resultados.

\section{Resultados y discusión}

En coherencia con la propuesta educativa y con la investigaciónacción - como praxis que articula la teoría con la práctica mediada por la reflexión-, la dinámica del proceso de codificación y descodificación se dio de manera emergente. Contrastar los elementos teóricos a la vez que se comprendía el contexto, implicó múltiples desafíos y aprendizajes, tanto para los educadores como para los educandos. A continuación, se presenta cómo la codificación y la descodificación apoyadas en TIC fueron dispositivos para la participación social y para comprender mejor la realidad social, así como para las reflexiones éticas generadas en esta experiencia investigativa.

\section{La codificación y descodificación apoyadas en TIC como dispositivos de participación social}

En esta experiencia, el diálogo fue la base del proceso educativo y a través del cual se favoreció el establecimiento de relaciones entre los sujetos para recrear el mundo; una forma de salir de la educación como mecanismo de reproducción. Se llevaron a cabo procesos dialógicos para la construcción de los códigos; esto es que, en la medida en que las participantes hacían una reflexión, construían conjuntamente a manera de síntesis una circunstancia que recogiera sus propias vivencias, preocupaciones, expectativas y situaciones límite.

Se construyeron códigos sobre temas tan diversos como el machismo, la relación de pareja, la aplicación de la norma y el castigo con los hijos, las oportunidades en la crianza, el estudio 
y los recuerdos sobre la crianza vivida. En este proceso, con las participantes se definía la forma de representar los temas que se querían problematizar. En ocasiones se recurría a que ellas interpretaran los personajes y se filmaba un video con sus propios celulares; otras veces construían un guion para grabarlo con sus propias voces en un audio. En algunos momentos se optó por la construcción de relatos que recogieran las experiencias que varias habían compartido en el círculo; y en otros se eligió llevar imágenes alusivas al contexto de la vereda o de la crianza para dinamizar las discusiones. En todas las modalidades, los códigos fueron los dispositivos que permitieron pasar de lo singular a lo común en la experiencia educativa.

Luego, al presentar el código para la descodificación, el diálogo fue el mecanismo de comunicación para avanzar en la problematización de las situaciones naturalizadas y pasar a visiones más críticas de la realidad. Decir la palabra y leer el mundo entre sujetos posibilita el paso hacia la concienciación (Freire, 2005; Freire, 1992; Freire, 1997). En este caso, la utilización de otros medios y modos abrió oportunidades para la expresión del pensamiento, para compartir saberes y discutirlos; una lectura del mundo que tenía como soporte lo digital. Las vivencias de las comunidades — sus experiencias personales y colectivas - no estuvieron al margen de las TIC. Incluso se observó la resignificación de las prácticas sociales con el uso de estas tecnologías (Giroux, 2001), en la medida en que las participantes las incorporaron en su cotidianidad.

Durante el proceso de codificación, se planteó la interrelación entre lo económico, político, social, familiar y personal. En este sentido, las relaciones familiares, que incluían a la pareja, madres, padres, hijos y cuñados, se veían afectadas por las dificultades económicas, el desarraigo, la violencia y las condiciones laborales precarias que atravesaban sus emociones, deseos, sueños y tristezas, que describían en su historia personal. Todo esto reflejaba las condiciones estructurales en que vivían y se hicieron visibles en las palabras que se identificaron a través del proceso comunicativo desarrollado con la construcción de los códigos. 
Por otra parte, es posible identificar nuevas estructuras del espacio social y transformaciones de lo público y lo privado, a través de los lugares de participación y movilización social que se configuran en los espacios digitales (Echeverría, 1999). En este sentido, el mundo digital representa oportunidades para encontrarse con otros, favorece la organización de colectivos con causas que los identifican y los unen frente a intereses, necesidades y deseos comunes. Muestra de ello son el Occupy Central with Love and Peace en Hong Kong, la Primavera Árabe en Medio Oriente y las Indignadas en España. Estos se han convertido en referentes de cómo las tecnologías se constituyen en un medio que fortalece los movimientos sociales, a través de las posibilidades comunicativas de interacción, trabajo en red y colaboración.

Desde el punto de vista relacional, la codificación y descodificación aportaron a las transformaciones de las participantes en cuanto a su relación consigo mismas. Los relatos dieron cuenta del desarrollo de su autonomía y autoestima en la medida en que se iban reconociendo como mujeres. También, cambiaron las formas de relacionarse con su pareja e hijos, y con ello fueron resignificando las crianzas que realizaban. Se hicieron más cercanas a otras participantes, fortaleciendo así sus redes de apoyo. De manera especial en el ejercicio de trabajo colectivo, la interacción entre mujeres con experiencias de vida similares permitió el desarrollo de solidaridad y empatía entre ellas, lo cual facilitó los procesos formativos.

En una línea similar, los investigadores tuvimos la oportunidad de proponer un trato dialógico que permitió que la relación educador-educando se reconfigurara. Para esto fue fundamental la confianza que se tejió entre los participantes, desde la cual se generaron sentimientos de afecto. Así, educador y educando crearon vínculos al construir comprensiones del mundo que los acercaban y los hacían partícipes de una misma realidad. Esto llevó al educando a comprender otras formas de ver el mundo, y al educador a entender que formar implica el reconocimiento de los contextos y las visiones de cada persona con la que interactúa para una transformación conjunta a través del proceso. En este sentido, uno de los investigadores planteó: nos transformamos juntos. 
Por otra parte, la ciudadanía, como práctica social, se fundamenta en la capacidad que tienen los sujetos para empoderarse en el espacio de lo público y construir lazos de afinidad con los territorios y con las personas que los habitan. El ejercicio de la ciudadanía se materializa al reconocer la necesidad de establecer acuerdos de convivencia para habitar el espacio de todos $y$, al mismo tiempo, valorar la alteridad y reconocer al otro como un igual, al que se debe valorar en su dignidad. En este sentido, la ciudadanía se construye en la medida en que los sujetos reconocen el lugar de sus actuaciones en el espacio de lo público y lo privado.

Al confrontar sus historias de vida, entender cuáles son sus orígenes y reconocer las experiencias vividas, los participantes pudieron proyectarse a futuro, para visualizar, en algunos casos, que existen posibilidades de cambios y expectativas diferente. Asimismo, el acto de compartir sus narrativas creó un sentimiento de solidaridad frente a las condiciones difíciles de vida que, en muchos casos, se comparten y que llevan a reconocer en el rostro del otro su propia historia. Un sentido similar al que plantea Levinás, al decir que se piensa en sí mismo al pensar en el otro (Levinas, 1997).

Comprender las vidas de manera intersubjetiva, plantea la formación como un aprendizaje desde el nosotros. En este caso, la preocupación por las necesidades conjuntas construyó lazos de solidaridad en medio de las diferencias. Las participantes se hicieron cómplices en las dificultades $y$, de modo colectivo, entendieron que existen alternativas a los problemas que son comunes a todas. Una de las participantes en los círculos planteó: "ojalá se pudieran traer otras personas porque hay muchas encerradas en la casa", haciendo alusión a la importancia de que otras mujeres se beneficiaran del proceso de aprendizaje.

La codificación y descodificación apoyadas en TIC como dispositivos de problematización para comprender mejor la realidad social

El uso de las TIC en este tipo de propuestas genera una reflexión pedagógica, en tanto se contemplan las características 
comunicativas y de construcción de significado que estas permiten y se vinculan con la intencionalidad del proceso pedagógico en sí. Es decir, abren nuevos espacios digitales y favorecen el uso de medios y modos. No obstante, es la propuesta pedagógica la que da sentido a las acciones para las cuáles se utilizan. De esta forma la tecnología se constituye como una herramienta de aprendizaje, una herramienta cognitiva (Aparicio, 2018). Desde lo comunicativo, un aspecto fundamental es que, de acuerdo con los modos utilizados para la codificación, se amplían las reflexiones que ayudan a comprender el potencial que tiene presentar el código en un audio, vídeo, dibujo o texto. Esto hizo parte de las decisiones que tomaron las dinamizadoras sobre cómo comunicar mejor sus reflexiones al resto del grupo.

Se entendió la importancia de la comunicación para el tejido de las relaciones comunitarias, por lo que expresar las situaciones límite de manera diversa, permitió avanzar hacia la reflexión. Aquí cobra sentido la alfabetización digital como asunto central, porque el sujeto puede acceder a espacios diferentes a los convencionales para interactuar con otros: "no solo nos ha de dar acceso a la información, sino que a través de esta, ha de proporcionarnos acceso al conocimiento" (Gutiérrez-Martín, 2003, p. 16). Este conocimiento, a su vez, ayudará y hará parte de procesos más complejos, como la comprensión del mundo, para expresar la palabra frente a aspectos de la vida en comunidad, que deben ser reflexionados para generar acción y transformación desde las acciones individuales y colectivas.

Por ello, el uso de las TIC no se vinculó a la enseñanza del uso de dispositivos o aplicaciones, sino que partió de las habilidades ya desarrolladas en su cotidianidad (como hablar con sus seres queridos distantes, tomar fotos de costuras o tejidos para realizarlos en sus casas o con amigas, recibir mensajes de las instituciones de salud y ver a los miembros de la familia a través de las redes sociales, entre otros). A partir de estas experiencias que tenían las participantes, se recreaban con otros propósitos desde el proceso de codificación-descodificación. Aquí el papel de la alfabetización se acercaría más a su propósito dignificante y liberador, 
más que "a una capacitación como usuario de cualquier nuevo dispositivo que vaya surgiendo" (Gutiérrez y Tyner, 2012, p. 32).

Los elementos que estaban encubiertos o aquellos sobre los que no existía reconocimiento desde una mirada crítica, se identifican a través de la reflexión sobre situaciones comunicativas cercanas que reflejan sus palabras, sus condiciones materiales. Al no tener incorporados los referentes de conocimiento para poder comprender las situaciones, no se es consciente plenamente; en este sentido, se requiere ampliar los conocimientos para extender la comprensión y así hacer la transición hacia una conciencia crítica. Por ejemplo, en la construcción y análisis de los códigos, representar desafíos sociales complejos - como las situaciones de violencia en la pareja - las llevó a problematizar las acciones propias y de los otros, sus causas y consecuencias, así como los límites y contradicciones de las tradiciones, los valores y las convicciones personales que tienen frente a estas (Bermúdez, 2015).

Todo esto estuvo fundamentado en procesos de análisis colectivo, reflexión crítica y reconstitución de las situaciones vividas desde una visión esperanzadora. Al respecto, Freire (2005) destaca que:

La inmediatez de la experiencia, mediada por la objetivación se hace lúcida, interiormente, en reflexión a sí misma y crítica anunciadora de nuevos proyectos existenciales. Lo que antes era enclaustrado, poco a poco se va abriendo; "la conciencia pasa a escuchar los llamados que la convocan siempre más allá de sus límites: se hace crítica. (p. 8)

En la descodificación se recrea de forma crítica el mundo a través del diálogo, se redescubren las relaciones en las situaciones límites que no permiten continuar. En esta experiencia, el papel de cocreación de los códigos favoreció la autocrítica a sus condiciones particulares representadas y el fortalecimiento de su capacidad para interrogar y desafiar prácticas, convenciones y discursos naturalizados: 
La "codificación" y la "descodificación" permiten al alfabetizando integrar la significación de las respectivas palabras generadoras en su contexto existencial: él la redescubre en un mundo expresado por su comportamiento. Cobra conciencia de la palabra como significación que se constituye en su intención significante, coincidente con intenciones de otros que significan el mismo mundo. Este, el mundo, es el lugar de encuentro de cada uno consigo mismo y con los demás. (Freire, 2005, p. 8)

Los contenidos digitales facilitaron la participación, porque permitieron que se expresaran las situaciones límites de cada contexto. También emergieron prácticas de democratización cuando se rompía el silencio generalizado en cuanto a las temáticas particulares (como el machismo y la violencia en la familia), las cuales se dinamizaban a través de un trabajo colaborativo y de coconstrucción con representaciones comunitarias.

Este es el caso de un código que se desarrolló sobre el abuso sexual infantil, donde el uso de la imagen asistió la reflexión a través de la creación de un collage comunitario con recortes de revista. Así, con la imagen, se abrió una forma diferente de nombrar lo que desde las narrativas e historias de vidas se hacía con la voz baja y el temor, dada las implicaciones éticas y sensibilidad del tema. Por ejemplo, en la construcción de la imagen surgieron preguntas que se plantearon en el colectivo como: ¿cuál es la imagen de un violador?, ¿qué estrategias utiliza un violador?, ¿quiénes están en mayor riesgo en la comunidad? entre otras, las cuales permitieron usar la palabra desde la representación de la imagen y se produjeron otras formas para pensar sus significaciones (Kress et ál., 2014).

En el proceso de descodificación, la creación de contenidos digitales y su distribución generó seguridad a las dinamizadoras. Desde su experiencia, encontraron una oportunidad de participar en el mundo digital, con el propósito de aportar a su comunidad. Por consiguiente, el uso de herramientas digitales no era el centro, sino el medio para un propósito de reflexión, que cada vez exigía 
el desarrollo de diferentes habilidades, tanto en el manejo de las herramientas como en los procesos de pensamiento (Ramírez, Carrillo y Calle, 2014).

Por ello, cuando los métodos de construcción de contenidos digitales se producen con escasa participación de la comunidad, las decisiones sobre el significado pasan por la interpretación de técnicos y profesionales expertos, quienes tienen otra lectura del mundo. En algunos casos, esto termina en acciones de exclusión (no intencionada) desde el mismo significado que se presenta. Es así como, la relevancia sobre la toma de decisiones que surge entre una temática y el modo que se elige, deja diferentes lecciones aprendidas. De igual manera, se presenta como reto la necesidad de una participación amplia de las comunidades al momento de crear contenidos educativos en educación para la salud.

La importancia del reconocimiento y el respeto sobre el saber social y cultural permitió que las experiencias del otro se abrieran como libros (con imágenes, videos, audios y texto de su realidad) para verse y comprenderse. Estos elementos cuestionaban las formas tradicionales de los papeles de los profesionales de la salud y la comunidad, donde, con frecuencia, se parte del desconocimiento del otro, o del saber del experto. Por el contrario, trajo consigo la reivindicación de los saberes populares, de acuerdo con los recorridos, tránsitos e historias; es decir, que está presente la pregunta y el interés por "su habla, su manera de contar, de calcular, sus saberes en torno al llamado otro mundo, su religiosidad, sus saberes en torno a la salud, el cuerpo, la sexualidad, la vida, la muerte" (Freire, 1992, p. 110).

Debido a la cercanía, los códigos presentaron familiaridad y un sentimiento de confianza para continuar navegando a través de ellos, como lo señala una participante: "esos videos sirven como para capacitarse en muchas familias, para ver si recapacitan y no se agreden unos a otros". En la curaduría de los contenidos digitales sobre crianza, en los videos se encuentran imágenes o se describen situaciones materiales que están alejadas de la realidad 
que vive esta comunidad. Es decir, se muestra un conflicto o situación problema común en la realidad de la crianza, pero en contextos diferentes a las de los destinatarios, con palabras que no tienen vinculación con sus prácticas y su mundo, o con soluciones muy discutibles desde sus posibilidades.

Las dinamizadoras entendían los códigos de diferentes maneras. En sus palabras, se referían a ellos como: "enseñanzas", "muestran cosas que uno no debe hacer", "le puede servir a uno mismo para aprender", "sirven para tratar los temas que a uno le preocupan", "sirven para ver si las personas reaccionan". Estas comprensiones correspondían a construcciones emergentes de la experiencia que estaban viviendo al construirlos y llevarlos a la descodificación con otras mujeres.

Los códigos se crearon desde una perspectiva crítica de la educación y prestaron atención a los fenómenos de significación, de acuerdo con las particularidades que hacen parte de la cultura y el entramado social (Serrano, 1998). En los códigos se evidenciaron las relaciones sociales cercanas que se expresaban desde las vivencias de las participantes. La tabla 1 presenta algunos ejemplos de las formas de relacionamiento que afloraron en los códigos.

Tabla 1. Formas de relacionamiento que se identificaron en los códigos.

\begin{tabular}{|c|c|c|c|}
\hline Audios & Videos & Imágenes & Textos \\
\hline $\begin{array}{c}\text { Conflictivas o de } \\
\text { diálogo entre madre } \\
\text { e hijo. }\end{array}$ & $\begin{array}{c}\text { De respeto, roles } \\
\text { entrevistado- } \\
\text { entrevistador. }\end{array}$ & De víctima y victimario. & $\begin{array}{c}\text { De reflexión consigo } \\
\text { mismo. }\end{array}$ \\
\hline $\begin{array}{c}\text { De amistad y } \\
\text { solidaridad entre } \\
\text { amigas. }\end{array}$ & $\begin{array}{c}\text { De amistad entre } \\
\text { vecinas. }\end{array}$ & & $\begin{array}{c}\text { De relación conflictiva } \\
\text { con la expareja. }\end{array}$ \\
\hline $\begin{array}{c}\text { De violencia de la } \\
\text { pareja. }\end{array}$ & $\begin{array}{c}\text { Conflictivas entre } \\
\text { familiares (marido, } \\
\text { mujer, cuñada y } \\
\text { suegra). }\end{array}$ & & \\
\hline $\begin{array}{c}\text { De tensión de la pareja. } \\
\text { pe amistad entre la } \\
\text { pareja de conflicto } \\
\text { con la familia. }\end{array}$ & & & \\
\hline $\begin{array}{c}\text { De violencia de la } \\
\text { pareja. }\end{array}$ & & \\
\hline la pareja. & Distanciamiento de & & \\
\hline
\end{tabular}

Fuente: elaboración propia. 
Además de volver y nombrar sus realidades y problematizar las formas de relacionamiento, todo esto implicó la participación y generación de roles, que derivaron en actividades concretas de edición colectiva de contenidos, construcción de guiones, actuación y grabación de videos, entre otros. Implicó también la negociación, acuerdos y discusión que fueron estrechando los vínculos entre las participantes. Expresiones como "me siento como más allegada a ellas, digámoslo así", reflejan procesos de relacionamiento y cercanía que se empiezan a tejer.

En la experiencia, se pudo dar cuenta del cambio de formas de vida a través de entramados tecnosociales, que encuentran otros medios de compartir el saber, nuevos modos de estar y actuar juntos en comunidad. En esta medida, decir "la expresión, la voz propia, los lenguajes de la multiplicidad, de la autoría compartida, distribuida, nos permiten pensar otros modos de estar con, de estar allí, de ser un nosotros, aunque este sea provisional y contingente" (Rueda, 2011, p. 9).

La descodificación trajo consigo un proceso de evaluación del código. En términos educativos, se pudo verificar cuáles elementos derivaron de la representación construida, qué tipo de reflexiones emergentes producía en contraste con las que se tenían por objetivo y de qué manera era recibido el código por su vinculación con las experiencias personales. También existió un proceso de retroalimentación, en el que las participantes expresaban lo que los códigos podrían incluir en un futuro.

Uno de los elementos discutidos con las participantes fue que ellas esperaban que los códigos presentaran una solución genérica para las situaciones límite planteadas. Sin embargo, no se trataba de desplegar una educación prescriptiva para homogeneizar las acciones, sino que se abría a la reflexión desde la premisa de la autonomía para la toma de decisiones. En consecuencia, con la descodificación se expandió el sentido del código que propuso Freire para ampliar los conocimientos, los procesos reflexivos y la comprensión, de forma que se pasó a buscar un escenario pertinente para la toma de decisiones $y$, por lo tanto, fortalecer 
la capacidad para la acción. Aquí también se problematizó si entregar estos contenidos dirigía o prescribía unas acciones. Esta reflexión dejó abierta la posibilidad de ir más allá del código para relacionarlo con otros temas que permitan una mirada comunitaria y más crítica de su realidad.

\section{Reflexión ética sobre los procesos de codificación y descodificación con TIC}

Como se trató de una investigación con participación de la comunidad, tuvo implicaciones como precepto epistemológico, en tanto que buscó dar voz a las participantes; sin embargo, no fueron ellas las responsables del proceso investigativo. De esta manera, fue posible encontrar caminos para asegurar unos principios clave de respeto a las personas y fomentar su participación en procesos democráticos para el mejoramiento de la vida humana a través de acciones moralmente comprometidas (Brydon, 2008).

Como respuesta a los principios éticos formulados y a la postura epistemológica del grupo de investigadores al reconocer que no hay una posición neutral y todas las investigaciones tienen intereses, hicimos explícita nuestra posición política hacia una perspectiva de justicia social, que nos ha comprometido con la lucha de las participantes en su búsqueda de mejores oportunidades para vivir la vida que consideran pertinente desde sus marcos valorativos.

En este tipo de investigación, la relación entre la cultura y la ética va más allá de un relativismo cultural, que impide la acción en las situaciones en que las gente está oprimida o en peligro (Lipson, 2003). Por lo tanto, para abordar la gran cantidad de asuntos éticos que surgieron durante el proceso, retomamos su propuesta de impregnar las decisiones éticas de: "sensibilidad cultural, conciencia con nuestros propios valores éticos [...] y confianza en nuestros sentimientos internos sobre lo que está bien en la situación inmediata y en si habrá repercusiones posteriores" (Lipson, 2003, p. 143). 
Con respecto a los daños potenciales que pudieran sufrir las participantes, es importante mencionar que en la investigación en ciencias sociales - a diferencia de la investigación en áreas biomédicas - pueden ocurrir situaciones inciertas, impredecibles e inherentes a la misma investigación (Guerriero y Bosi, 2015). Sin embargo, como afirma Cassell: "la mayoría de los daños y beneficios del trabajo de campo son menos inmediatos, medibles y serios que los daños asociados con otros modos de investigación" (como se citó en Lipson, 2003. p. 5).

En coherencia con los fundamentos epistemológicos que guiaron la investigación, la dimensión ética se consideró como un asunto intrínseco al proceso. De esta forma, se reconoció al investigador como sujeto moral; en este sentido, la práctica investigativa estuvo configurada también por dilemas morales que se afrontaron de manera permanente. Por ejemplo, en relación con la difusión de los códigos en video que se realizaron, se tomó la decisión de no divulgarlos para ejercicios educativos en comunidades diferentes, porque esto implicaba exponer a las participantes y correr el riesgo de que fueran vulneradas.

De igual forma, la construcción de los códigos se hizo con las participantes y se consideró que quienes apoyaran las grabaciones no fueran agentes externos, sino que fueran ellas mismas quienes asumieran el uso de tecnologías como el celular. Debido al deseo de conservar la esencia de lo que querían comunicar y los elementos del contexto que deseaban visibilizar, se estableció que un sujeto externo no tenía las vivencias para construir significado desde el sentir y el vivir. Este elemento reivindicó el proceso del papel del educador-educando, en tanto que querían tomar las decisiones sobre qué decir y cómo decirlo a través del código. En un sentido similar, las participantes se asumieron como responsables de sus conversaciones en el espacio del círculo y, por lo tanto, establecieron sus propios acuerdos de confidencialidad. Este fue un pacto que permitía revelar el código desde lo pertinente, lo que se puede denominar afuera del círculo. 
Es importante destacar que no se llevó a cabo un curso de alfabetización digital para el desarrollo de habilidades, sino que a partir de la construcción del código surgió el interés de utilizar sus propios recursos; es decir, extender el uso cotidiano que tenían de las TIC para asistir y definir el sentido de cómo usarlos. Identificamos que en esta comunidad había una brecha digital para el acceso a la tecnología, debido a las limitaciones para acceder a los servicios como la red de internet y los dispositivos con buena resolución y sonido por los altos costos.

\section{Consideraciones finales}

La codificación y descodificación con las participantes, mediante el uso de las TIC, en el marco de la investigación temática tiene fortalezas como la estrategia para el desarrollo de la educación popular en salud. Esta permite llevar a cabo un proceso educativo problematizador y potencia las acciones derivadas de la reflexión propia. En cuanto al desarrollo metodológico en sí, no es posible definir una serie de pasos establecidos para su formulación; se construye entre educadores y educandos de acuerdo con las necesidades. De allí la importancia de la flexibilidad para atender las categorías emergentes e intereses que se reconfiguran en el proceso.

La manera de llevar a cabo la investigación-acción, imbricada con la educación, potenció la reflexividad, el diálogo, la participación y la coconstrucción. De igual manera, se exploraron distintas formas de compartir con otros y se avanzó en la construcción de posibilidades para que cada participante definiera las acciones que le permitieran realizar cambios en su cotidianidad. Si bien es necesario reconocer que una investigación por sí sola no alcanza a cambiar las circunstancias adversas del entorno, permitió un ejercicio de concienciación y de toma de posturas sobre las condiciones de opresión.

Esta experiencia — novedosa para los investigadores - trajo consigo lecciones en relación con los procesos educativos en crianza 
desde perspectivas alternativas. Esto en la medida en que se integraron formas de construcción de conocimientos que favorecieron que la problematización y las realidades intersubjetivas se abordarán a través de lo oral, lo textual, el gesto o la imagen.

Finalmente, también fue valioso el reconocimiento de los saberes de las participantes sobre la crianza como punto de partida de la codificación y descodificación. Esto dio lugar a relaciones horizontales entre los actores. Dicha forma de relacionamiento correspondió a una construcción de empatía y confianza, que, sin desdibujar los roles del educador y el educando, estrechó los vínculos entre ambos. Esta experiencia constituye un referente sobre formas alternativas para llevar a cabo procesos de educación para la salud y la crianza, que puede tener continuidad y ser llevada a otros escenarios con comunidades que tengan condiciones similares de injusticia social.

\section{Referencias}

Aparicio, O. (2018). Las TIC como herramientas cognitivas. Revista Interamericana de Educación, Pedagogía y Estudios Culturales, 11(1), 67-80.

Bermúdez, A. (2015). Four Tools for Critical Inquiry in History, Social Studies, and Civic Education. Revista de Estudios Sociales, 4(52), 102-118. https://doi.org/http://dx.doi.org/10.7440/res52.2015.07

Bradbury, H. y Reason, P. (2003). Issues and choice points for improving the quality of action research. En M. Minkler y N. Wallerstein (eds.), Community-Based Participatory Reseach for Health (pp. 225-239). JosseyBass.

Brydon, M. (2008). Ethics and Action Research: Deepening our Commitment to Principies of Social Justice and Redefining Systems of Democratic Practice. En P. Reason y H. Bradburry (eds.), The SAGE Handbook of Action Research. Participative Inquiry and Practice (2 $2^{\mathrm{a}}$ ed., pp. 199-209). SAGE Publications. 
Castells, M. (2001). La era de la información: economía, sociedad y cultura Volumen I. La sociedad red. Siglo Veintiuno editores.

Echeverría, J. (1999). Telépolis. Ediciones Destino, S.A.

Fals Borda, O. (2001). Participatory (Action) Research in social theory: origins and challenges. En P. Reason y H. Bradbury (eds.), Handbook of action research: Participative inqyuiry and practice (pp. 27-37). SAGE Publications.

Freire, P. (1992). Pedagogía de la esperanza. Un reencuentro con la pedagogía del oprimido. Siglo XXI.

Freire, P. (1997). Pedagogía de la autonomía. Saberes necesarios para la práctica educativa. Siglo XXI.

Freire, P. (2005). Pedagogía del oprimido. Siglo XXI.

Giroux, H. (2001). Cultura, política y práctica educativa. Grao.

Guerriero, I. C. Z. y Bosi, M. L. M. (2015). Research ethics in the dynamic of scientific field: challenges in the building of guidelines for social sciences and humanities. Ciência \& Saúde Coletiva, 20(9), 2615-2624. https://doi.org/10.1590/1413-81232015209.06022015

Gutiérrez-Martín, A. (2003). Alfabetización digital. Algo más que botones y teclas. Editorial Gedisa.

Gutiérrez-Martín, A. y Tyner, K. (2012). Educación para los medios, alfabetización mediática y competencia digital. Revista Científica de Educomunicación, XIX(38), 31-39.

Kress, G., Jewitt, C., Ogborn, J. y Tsatsarelis, C. (2014). Multimodal teaching and learning. The rhetorics of the science classroom. Bloomsbury Academic.

Landow, G. P. (2009). Hipertexto 3.0. Teoría crítica y nuevos medios en el área de la globalización. Paidós. 
Levinas, E. (1997). Fuera del sujeto. Caparrós.

Lipson, J. (2003). Asuntos éticos en la etnografía. En J. Morse (ed.), Asuntos críticos en los métodos de investigación cualitativa (pp. 389-415). Universidad de Antioquia.

Martín, J., Sunkel, G., Bello, M. N., Vega, N. P. y Valenzuela, J. M. (2005). América Latina, otras visiones desde la cultura. Ciudadanias, juventud, convivencia, migraciones, pueblos originarios, mediaciones tecnológicas. Convenio Andrés Bello.

Mejía, M. R. (2013). La educación popular: una construcción colectiva desde el sur y desde abajo. Bogotá: Seminario Internacional de Educación Popular organizado por el Centro de Investigación y Educación Popular (CINEP) y la Alcaldía Mayor de Bogotá. Convenio Andrés Bello.

Peñaranda, F. (2011). La crianza como complejo histórico, sociocultural y ontológico: una aproximación sobre educación en salud. Revista Latinoamericana de Ciencias Sociales, Niñez y Juventud, 2(9), 945-956.

Ramírez, D. A., Carrillo, S. C. y Calle, G. Y. (2014). Alfabetización: una ruta de aprendizaje multimodal para toda la vida. Consideraciones sobre las prácticas de lectura y escritura para el ejercicio cuidadano en un contexto global e intercomunicado. Universidad de Antioquia.

Rueda, R. (2011). De los nuevos entramados tecnosociales: emergencias políticas y educativas. Folios, 33, 7-22.

Serrano, M. (1998). La Educación para la Salud Del Siglo XXI. Comunicación y Salud. Díaz de Santos.

Torres, A. (2011). Educación Popular. Trayectoria y actualidad. Universidad Bolivariana de Venezuela.

Villa-Vélez, L. (2020). Educación Para la Salud y Justicia Social basada en el Enfoque de las Capacidades: Una oportunidad para el desarrollo de la Salud Pública. Ciênc. Saúde Coletiva, 25(4), 1539-1546. https://doi. org/10.1590/1413-81232020254.19052018 
Zanchetta, M. S., Kolawole-Salami, B., Perreault, M. y Leite, L. C. (2012). Scientific and Popular Health Knowledge in the Education Work of Community Health Agents in Rio De Janeiro Shantytowns. Health Education Research, 27(4), 608-623. https://doi.org/10.1093/her/ cys072 